\title{
THE INFLUENCE OF PLASTICIZER IN NAIL LACQUER FORMULATIONS ON FLUCONAZOLE PERMEABILITY THROUGH THE BOVINE HOOF MEMBRANE
}

\author{
ALISA ELEZOVIĆ'*, AMAR ELEZOVIĆ ${ }^{2}$ and JASMINA HADŽIABDIĆ ${ }^{1}$ \\ 'Department of Pharmaceutical Technology, Faculty of Pharmacy, University of Sarajevo, \\ Zmaja od Bosne St. 8, 71000 Sarajevo, Bosnia and Herzegovina \\ ${ }^{2}$ Control Laboratory of Agency for Medicinal Products and Medical Devices of Bosnia and Herzegovina, \\ Titova St. 9, 71000 Sarajevo, Bosnia and Herzegovina
}

\begin{abstract}
Medicinal nail lacquers are the most effective topical treatment of nail diseases. These formulations generally are organic solutions of the active substance as well as film-forming polymer and plasticizer, which affects the characteristics of the film formed after application and solvent evaporation. The aim of this work was to test the effects of plasticizer present in nail lacquer formulations on permeation kinetics of fluconazole through the bovine hoof membrane in a novel in vitro test. The formulations contained Eudragit RS100 dissolved in acetone, and dibutyl-phthalate, PEG 400 or propylene glycol as plasticizers present in two different concentrations. Permeation studies were carried out during the 7-day period, and the obtained permeability profiles analyzed using similarity and difference factors, and by model-dependent permeation kinetics. When analyzed within the same strength, the highest extent of fluconazole permeation was obtained from the formulation with a lower concentration of propylene glycol at $0.9 \%$ fluconazole concentration, while for formulations with $1.8 \%$ and $2.7 \%$ of fluconazole, the highest permeation was achieved from the formulation with the higher content of PEG400. The permeation profiles showed a greater difference within one formulation of different fluconazole content than with the same plasticizer present in different concentrations, when using dibutylphthalate and PEG400. The permeation profiles were similar when using propylene glycol. When comparing formulations with the same concentrations of plasticizers, there were differences in formulations with the higher fluconazole concentrations. Permeation kinetics depended on fluconazole concentration as well as the path length the active substance had to pass to reach the receptor solution.
\end{abstract}

Keywords: plasticizer, fluconazole, nail lacquer, in vitro permeability, bovine hoof membrane

Onychomycoses, fungal nail infections, constitute up to $50 \%$ of all nail disorders (1). The incidence is $2-10 \%$ of the population, and in some countries up to $18 \%$ (2). The incidence increases with age, and the estimates are that $48 \%$ of the population over age 70 is affected (3). These numbers are estimates, due to difficulty in determining the exact numbers. A lot of those affected do not visit a doctor since they do not see it as a serious enough condition. It has to be kept in mind that the therapy is quite long, a lot of patients do not respond to the treatment, and in the case of systemic therapy, there are several serious side effects due to the long period of application of potent antifungal agents.

The risk factors for onychomycoses include age, genetic and atopic predispositions, family his- tory, poor general health, frequent nail traumas, contact with pathogens from the environment, warm and humid climate, sport activities, use of common showers, occlusive clothes and footwear, imunosuppression, prevalence of tinea pedis and diabetes (4). Onychomycoses can be treated either by removing the diseased nail plate and applying systemic or topical treatment (1).

Topical treatment avoids the shortcomings of systemic treatment. However, the drug diffusion into the highly keratinized nail plate is slow, treatment duration is a long and topical treatment, for now, is recommended in the early stages of the disease and when only one or two nails are affected, as well as when the systemic therapy is contraindicated. In more difficult cases and those not reacting to

* Corresponding author: e-mail: alisa.elezovic@ffsa.unsa.ba 
the systemic mono treatment, the dual therapy, both systemic and topical, is recommended. Different combinations of such therapy proved more effective than monotherapy.

Topical formulations used conventionally in dermatology (ointments, creams, gels, lotions, and powders) are not suitable for the nail or the usual length of treatment (6-12 months). After the application of such formulations, they easily get wiped or washed away, thus their inefficacy can be explained by their transiency at the site of action (5). Instead of these formulations, new formulations are proposed. The most appropriate formulations are nail lacquers or film-forming solutions that contain antifungal agents. Like cosmetic nail lacquers, they are applied to the nail plate using a brush and they dry fast leaving a water-insoluble film. The drug is released from the film and enters the nail plate (6).

Film-forming formulations are developed to give effective doses of antifungal agents into the nail plate during short (1 day) or long (up to 1 week) time period. This enables less frequent applications, while the effective therapy is achieved with high bioavailability of the active substance. Film on the nail plate surface acts as a depot of the active substance and enables optimized and continuous diffusion of the drug. Continuous penetration of the active principle leads to the high concentrations in the nail tissues necessary for the effective treatment of onychomycoses (1).

Medicinal nail lacquers are relatively new formulations named ,transungual drug delivery systems" (4). Besides the requirements common for both cosmetic and medicinal nail lacquers $(7,8)$, there are further requirements for medicinal nail lacquers: they have to be transparent and without shine, making them acceptable to male patients, and the drug has to be able to leave the film and penetrate the nail (1).

These formulations are basically organic solutions of film-forming polymer and active substance. When applied to the nail plate, the organic solvent evaporates leaving the drug-containing polymer film. The drug is slowly released from the film and penetrates the nail plate and nail bed. The drug concentration in the film is much higher than in the original formulation, due to the solvent evaporation (e.g. in Loceryl ${ }^{\circledast}$ lacquer the amolorfine concentration is $5 \%$, while it is $25 \%$ inside the film). This high concentration causes increased transungual diffusion of the drug, due to the increased diffusion gradient. Film formation on the nail plate also reduces water evaporation from the nail plate surface, thus causing hyperhydration of the upper nail layers, further increasing diffusion into the nail (5).
Polymer film containing drug could be viewed as a matrix type delivery system with controlled release (monolithic matrix), where the drug is dissolved or dispersed in polymer. It is assumed that the dispersed substance will be dissolved in polymer film before diffusion, which will be led by Fick's law of diffusion.

The drug release will also be limited by the drug molecule distribution from the film to the nail plate, and the distribution coefficient is defined as the ratio of solubility of the drug in the nail plate and solubility in the polymer film. Nail plate penetration of the active substance after the topical nail lacquer application, thus, depends on solubility in the polymer film, solubility in the nail plate, diffusion coefficient in the polymer film, diffusion coefficient in the nail plate and the content of the active substance in the film.

In these formulations, the plasticizer is commonly present. Plasticizers can be hydrophilic or lipophilic. They change mechanical characteristics of the film, such are flexibility, film hardness and adhesive properties, compared to the polymer alone, which is brittle and fragile without a plasticizer (9). The plasticizer effect is based on the decrease of forces of attraction between the polymer chains. A weakening of the attraction forces leads to the increased mobility of the macromolecules. The extent to which the plasticizer decreases intermolecular attraction forces between the molecules depends on its chemical structure, the possibility of the interactions with polymer chains and its hydrophilicity (10). The increase of the plasticizer content leads to the decrease of the attraction forces between the polymer chains simply due to the increase in a number of plasticizer molecules located between the macromolecules (11). Until now there was a relatively small number of authors studying the change in drug release kinetics due to the plasticizer used in polymer films, while generally the mechanical characteristics of the film formed were studied $(11,12)$.

\section{Perungual absorption of drugs after topical appli- cation}

After the topical application of a formulation on the nail plate, the drug has to penetrate the nail and diffuse in deeper nail layers and possibly into the nail bed (1). It was found that the nail plate behaves as a concentrated hydrogel, rather than lipophilic membrane (unlike the other body membranes) (13). When the diffusion of the molecules through the nail was compared to the diffusion of nonelectrolytes through the polymers, it was proposed that thermal movement of the keratin fibers in 
the nail would create holes (,pores“), that would then be occupied by diffusing molecules. Along with the ,pore“ mechanism, the substance transport through the nail can happen by partition mechanism. In this case, the substance would be distributed in the polymer-keratin network and diffuse through the polymer segments. The partition coefficient would be under the influence of hydrophobic and electrostatic interactions between the keratin network fibers and molecules (1).

Transungual transport of drugs is affected by physicochemical characteristics of the drug molecule (e.g. size, shape, charge, hydrophobicity), characteristics of the formulation (e.g. nature of the vehicle, $\mathrm{pH}$, drug concentration), presence of penetration enhancers, nail characteristics (e.g. thickness, hydration), as well as the interaction of the penetrating molecule and nail keratin network (1).

Fluconazole is a synthetic antifungal agent with rather favorable characteristics for transungual transport compared to the other azoles. Its molecular mass is relatively small $(306.27 \mathrm{Da}$, compared to ketoconazole - 531.43 Da, myconazole - 416.13 Da, econazole - 381.68 Da, itraconazole - 705.63). It is more hydrophilic (or less lipophilic) with $\log \mathrm{P}$ 0.5 , compared to ketoconazole $(\log \mathrm{P}=3.5)$ and itraconazole $(\log \mathrm{P}=5.7)$ and fluconazole binds less to proteins. Its ionization constant $(\mathrm{pKa})$ is $1.76 \pm 0.10$ at $24^{\circ} \mathrm{C}$ in $0.1 \mathrm{M} \mathrm{NaCl}$ solution. It is a week base and gets protonated at N-4 nitrogen (Fig. 1) (14).

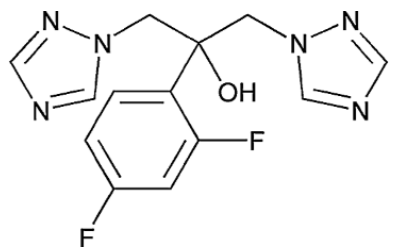

Figure 1. Structural formula of fluconazole.

\section{Permeation studies}

Since transungual drug delivery system has to be able to release the drug into the nail plate, one of the crucial tests is penetration of the drug into the nail plate or permeation through the nail plate, primarily in vitro. It cannot be said that the methods for the drug permeation testing from different formulations into the nail are standardized. Scientific teams developing different formulations, from ointments to nail lacquers and nail patches, develop their own methods.

Healthy or diseased nails from volunteers or patients let to grow for at least a month $(2,15-17)$ or cadaver nails (1) are used as membranes in permeation in vitro studies. Kobayashi et al. (15) found that the permeability through healthy and diseased nails was not significantly different, thus the permeability through the diseased nail can be estimated from the permeability through the healthy nail. However, newer findings of Cutrín Gómez et al., who compared the in vitro permeability of relevant active substances from solutions through onychomycotic, psoriatic and healthy nails, found ,that the microstructural modifications produced by the pathologies can alter significantly the permeation of drugs". This was more pronounced in onychomicotic nails, where the keratolytic activity of the fungi led to the more porous structure with fewer disulfide bridges across. The result was greater rate and extent of diffusion of the drug (cyclopirox olamine) through the onychomycotic nail, compared to the healthy one. The authors argue that this may be good at the beginning stages of the therapy of very diseased nails. However, in order for the formulations to be effective during the whole course of treatment, they have to be made effective as the nail recovers its healthy structure, and thus barrier function, as well (17).

Porcine hooves $(18,19)$ and bovine hooves $(1$, $16,20)$ are also used. Bovine hooves are used, since they are more readily available than human nails, and after the pretreatment (cleaning, drying, hydration), they are cut to the membrane of specific thickness. It is found that the permeability coefficient through the human nail can be estimated if the bovine membrane permeability coefficient is known using Equation 1:

$$
\log P_{N}=3.723+1.751 \log P_{H}
$$

Where $P_{N}$ is nail permeability coefficient, and $P_{H}$ is hoof membrane permeability coefficient. Permeability coefficient is defined as product of the drug diffusion coefficient (D) through the nail/hoof barrier and drug partition coefficient $(\mathrm{K})$ between vehicle and the barrier, $\mathrm{P}=\mathrm{DK}\left(\mathrm{cm}^{2} / \mathrm{s}\right)$, while some authors define it as $\mathrm{P}=\mathrm{DK} / \mathrm{h}(\mathrm{cm} / \mathrm{s})$, where $\mathrm{h}$ is nail thickness (1).

When using hoof as a model for human nail, it must be kept in mind that the hoof is more permeable and swells more (36\% vs. $27 \%$ ), and its proteins have less disulfide linkages than a nail. As a result, the hoof can be less susceptible to the substances that break down the disulfide bonds and are studied as potential perungual penetration enhancers. In these instances, perungual absorption through the hoof could be less increased than penetration enhancement that would be achieved in the human nail (1).

These analyses were carried out mostly using modified Franz diffusion cells, where the tested 
preparation was applied to the membrane fitted to the diffusion cell (with one compartment - receptor). However, in some cases the Franz diffusion cells with two compartments were used, receptor compartment consisting of the water or buffer solution of the active substance $(15,17,20)$. Receptor solution is either distilled water or buffer in contact with the membane. Myong et al. (19) used poloxamer gel, which they periodically changed and extracted the active substance. Christensen et al. (16) used agar plates seeded with an inoculum of Trichophyton spp. The medium temperature varies from method to method from $32^{\circ} \mathrm{C}(19), 35^{\circ} \mathrm{C}(20)$, $37^{\circ} \mathrm{C}(15,17)$, up to $40-45^{\circ} \mathrm{C}(18)$. Samples of the receptor medium were taken in the set time intervals - every few hours (2) to few days $(16,17,19)$, depending on study design, and then assayed directly or after derivatization.

The other method used by Hui et al. was to use radiolabeled active substances incorporated into the preparation. After the set time, the radioactivity of the nail samples from different nail layers was measured. This method has the advantage of measuring the drug content in different nail layers after a certain time period, which is not possible with the other described methods. However, the disadvantage is complexity and exposure to radioactive substances $(3,21)$.

The number of replicates in permeation studies varies from 3 to 8 (1).

The aims of this study were to develop nail lacquer formulations of fluconazole with varying nature and concentrations of plasticizer and to determine the rate and the extent of permeation of fluconazole in vitro through the bovine hoof membrane as well as the effects of plasticizer on permeation kinetics.

\section{EXPERIMENTAL}

\section{Materials}

Eudragit RS 100 was a kind gift from Evonik Industries AG, Germany. Fluconazole and flucona- zole working standard (99.54\%) were from Matrix Laboratories, India. The plasticizers used were dibutil-phthalate (Panreac, Spain), polyethylene glycol 400 (Lex, Slovenia) and propylene glycol (Semikem, Bosnia and Herzegovina). The vehicle was acetone (Alkaloid, North Macedonia). Disodium hydrogen phosphate, potassium dihydrogen phosphate and sodium chloride were from Semikem, Bosnia and Herzegovina.

Hoof membranes were obtained from a local slughterhouse (Šahbaz, Bosnia and Herzegovina).

\section{Methods \\ Preparation of the nail lacquer formulations}

The formulations were prepared as acetone solutions of the active substance and excipients on magnetic stirrer MR 1000 (Heidolph, Germany) with the content shown in Table 1.

The same formulations were also prepared in double and triple strength, with fluconazole content of $1.8 \%$ and $2.7 \%$, respectively, and acetone amount adjusted accordingly.

\section{Permeability studies}

The bovine hoofs were taken from the local slaughterhouse from freshly slaughtered calves. After washing with water, membranes of $200 \pm 50$ $\mu \mathrm{m}$ thickness were cut with mench plane and shaped into circles of $8.0 \mathrm{~mm}$ diameter. They were shortly washed in mild detergent solution, then water and dried in the air. The thickness of each membrane was measured and recorded.

The hoof membrane circle was set inside the vial cap that was hollow in the middle (the effective surface for permeation was $0.1963 \mathrm{~cm}^{2}$ ). On the membrane from the outer side of the cap, $30 \mu \mathrm{L}$ of the formulation was set and dried in the air for $1 \mathrm{~h}$.

Three vials $(\mathrm{V} \approx 1.8 \mathrm{~mL}$ ) were glued on the cap of a glass jar. After filling each vial with $1.5 \mathrm{~mL}$ of isotonic phosphate buffer $\mathrm{pH} 7.4$ (receptor medium), earlier prepared vial caps were used to close the vials. The glass jar was then closed with such cap, with vials turned upside down, as shown in Figure 2,

Table 1 . The content $(\% \mathrm{w} / \mathrm{v})$ of the formulations.

\begin{tabular}{|c|c|c|c|c|c|c|}
\hline $\begin{array}{ll}\text { Substance } & \text { Formulation } \\
\end{array}$ & $1 \mathrm{~L}$ & $2 \mathrm{~L}$ & $3 \mathrm{~L}$ & $4 \mathrm{~L}$ & $5 \mathrm{~L}$ & $6 \mathrm{~L}$ \\
\hline Fluconazole (g) & 0.9 & 0.9 & 0.9 & 0.9 & 0.9 & 0.9 \\
\hline Eudragit RS100 (g) & 18 & 18 & 18 & 18 & 18 & 18 \\
\hline Dibutyl phthalate $(\mathrm{g})$ & 2.7 & 4.5 & - & - & - & - \\
\hline Polyethylene glycol 400 (g) & - & - & 2.7 & 4.5 & - & - \\
\hline Propylene glycol (g) & - & - & - & - & 2.7 & 4.5 \\
\hline Acetone (mL) & ad 100 & ad 100 & ad 100 & ad 100 & ad 100 & ad 100 \\
\hline
\end{tabular}




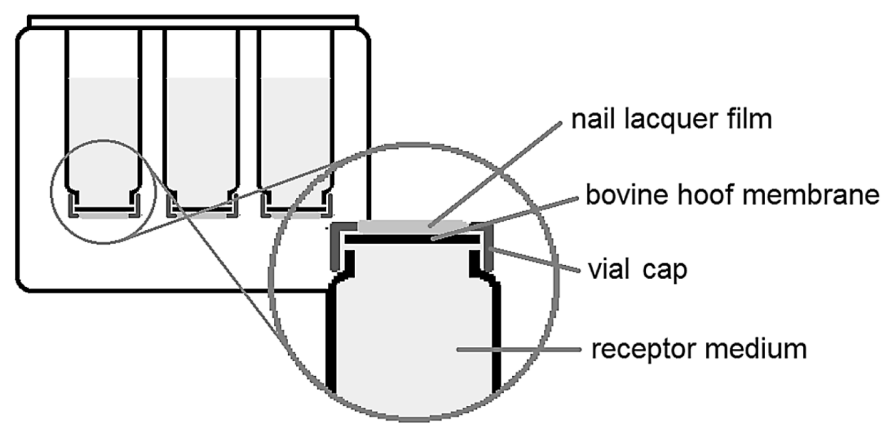

Figure 2. System for permeation testing of fluconazole from transungual delivery system through bovine hoof membrane.

and thermostated at $32^{\circ} \mathrm{C}$ (water bath). The samplings were performed after $1,3,5$ and 7 days, each in six replicates.

In clean and dry quartz cuvette $(\mathrm{d}=1 \mathrm{~cm}) 1 \mathrm{~mL}$ of the receptor medium sample was measured and diluted by $1 \mathrm{~mL}$ of isotonic phosphate buffer $\mathrm{pH}$ 7.4. The absorbance was measured at $261.0 \mathrm{~nm}$ on UVVIS spectrophotometer UV-1601 (Shimadzu, Japan) against isotonic phosphate buffer $\mathrm{pH} 7.4$, and concentration obtained from the calibration curve. The spectrophotometric method was previously validated for linearity, repeatability, specificity (interference), and limits of detection and quantification according to the ICH Guideline Q1-R2 (22).

\section{Permeation profiles comparison}

With the aim of obtaining more complete kinetics data for fluconazole permeation from the nail lacquer formulations, formulations with $1.8 \%$ and $2.7 \%$ of fluconazole (thus, double and triple concentrations) were made and the same method of permeation testing was carried out.

For all three strengths of all formulations, the permeation profiles were made. The permeation profiles were compared using difference and similarity factors ( $f_{1}$ and $f_{2}$ ), which are usually used for the comparison of dissolution profiles of oral dosage forms. Difference and similarity factors were calculated using the equations 2 and 3:

$$
\begin{gathered}
f_{1}=\frac{\sum_{\mathrm{t}=1}^{\mathrm{n}}\left|\mu_{R i}-\mu_{T i}\right|}{\sum_{\mathrm{t}=1}^{\mathrm{n}} \mu_{R i}} \\
f_{2}=50 \cdot \log \left[\frac{100}{\sqrt{1+\frac{\sum_{i=1}^{t=n}[\bar{R}(\mathrm{t})-\bar{T}(\mathrm{t})]^{2}}{n}}}\right]
\end{gathered}
$$

Where: $\bar{R}(\mathrm{t})$ - mean percent of released/permeated active substance from reference formulation in time $\mathrm{t} ; \bar{T}(\mathrm{t})-$ mean percent of released/permeated active substance from test formulation in time $\mathrm{t} ; n$ - number of sampling points

The permeation profiles are considered similar if the value of difference factor $\left(f_{1}\right)$ is less than 15 , and the values of similarity factor $\left(f_{2}\right)$ is between 50 and 100 (23).

\section{Model dependent permeation kinetics}

The fitting of the permeation profiles was performed to the mathematical models describing the kinetics of zero order, first order and Higuchi model. Pharmaceutical forms that release the active substance by zero-order kinetics are releasing the same amount of the substance per unit time, according to the equation 4 :

$$
Q_{t}=Q_{0}+K_{0} t
$$

Where: $Q_{t}-$ amount of the active substance released/permeated in time $t, Q_{0}$ - initial concentration of the substance in solution (receptor medium), $K_{0}$ - zero-order dissolution/permeation rate constant (24).

This system is suitable for achieving prolonged release.

The first-order model can be presented as follows (equation 5):

$$
Q_{t}=Q_{0} \mathrm{e}^{-K_{1} t}
$$

Or equation 6:

$$
\log Q_{t}=\log Q_{0}+\frac{K_{1} t}{2.303}
$$

Where: $Q_{t}$ - amount of substance released/permeated in time $t, Q_{0}$ - initial concentration of the substance in solution (receptor medium), $K_{l}$ - first-order release/permeation constant (25).

In the dosage forms that follow this release/permeation model, the active substance is 
released or permeates in such manner that it is proportional to the amount of the substance that stays in the dosage form. Thus, the amount released decreases with time. It can be used to describe the release/permeation of the active substances soluble in water (sometimes even sparingly soluble) in a porous matrix (26).

Higuchi model was the first model that describes the release/permeation of the active substance from the matrix system. This model is used as it is based on the premises that might be expected of release of a substance from nail lacquers, such as: the substance diffuses in one dimension, matrix swelling and its dissolution are negligible, the substance diffusion is constant and the perfect sink conditions are always present during release/permeation (27).
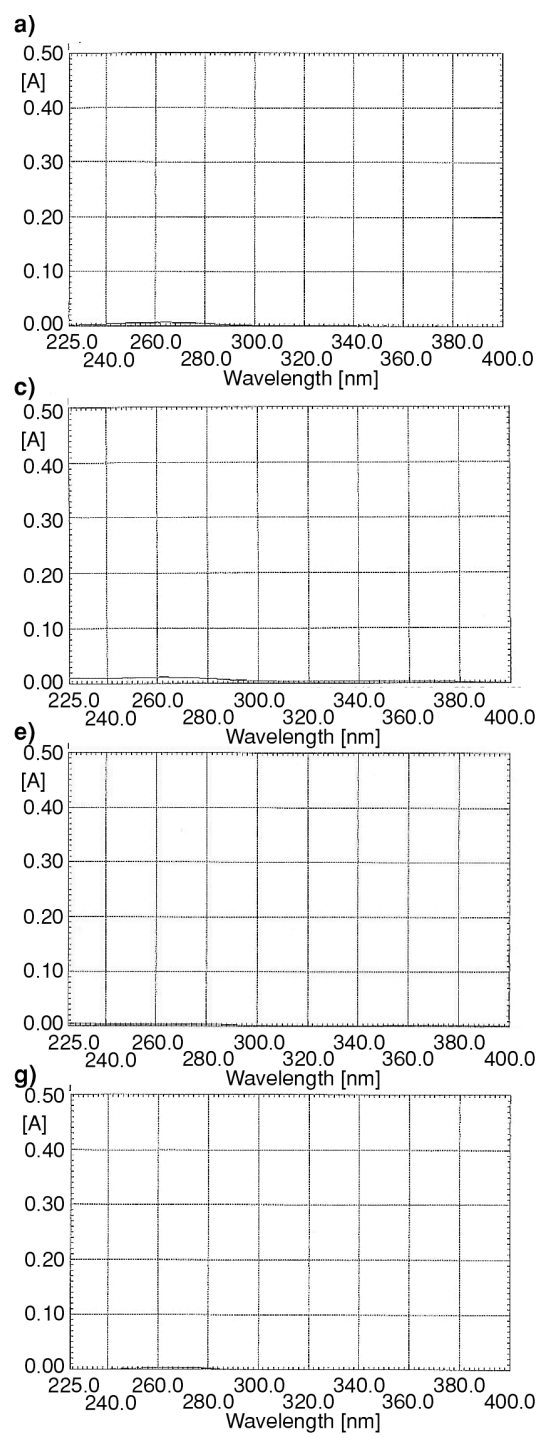

This model can be presented with simplified equation 7:

$$
f_{1}=Q=K_{H} \sqrt{t}
$$

Where: $K_{H}$-Higuchi release/permeation rate constant.

This model follows matrix formulations from which the substance is released/permeates by diffusion (26).

The data processing was carried out in MS Excel $^{\circledR}$.

\section{RESULTS}

The spectrophotometric assay was validated in the range of $10.14-506.91 \mu \mathrm{g} / \mathrm{mL}\left(\mathrm{R}^{2}=0.999994\right)$, and calculated limit of detection was $1.7626 \mu \mathrm{g} / \mathrm{mL}$

b)

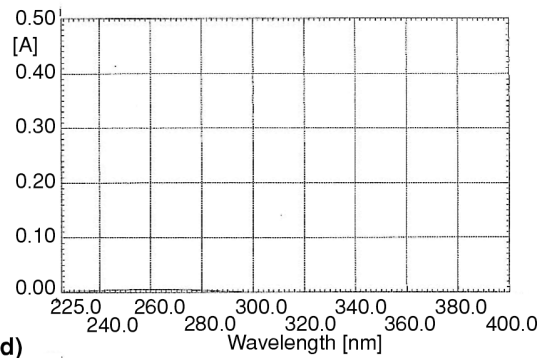

d)
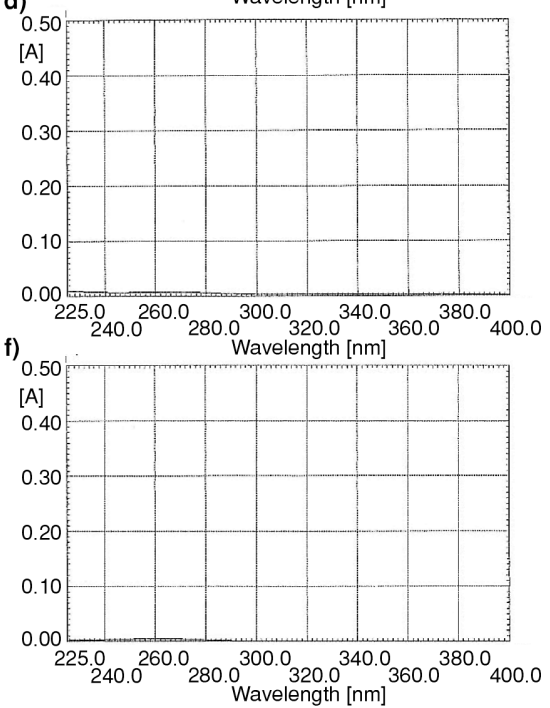

Figure 3. Spectra $(\lambda=225-400 \mathrm{~nm})$ of blank-formulations 1B-6B $(\mathrm{a}-\mathrm{f})$, and without formulations $(\mathrm{g})$ after carrying out permeation method through the bovine hoof membrane. 
Table 2. Comparison of the same formulations with different strengths (value of the factors indicating difference are bolded).

\begin{tabular}{|c|c|c|}
\hline $\begin{array}{c}\text { Formulations } \\
\text { compared }\end{array}$ & $\mathrm{f}_{1}$ & $\mathrm{f}_{2}$ \\
\hline 1L0.9-1L1.8 & $\mathbf{6 4 . 0 2}$ & $\mathbf{3 4 . 5 8}$ \\
\hline 1L0.9-1L2.7 & $\mathbf{5 6 . 6 9}$ & $\mathbf{3 5 . 5 5}$ \\
\hline 1L1.8-1L2.7 & $\mathbf{1 6 . 2 4}$ & 58.25 \\
\hline 2L0.9-2L1.8 & $\mathbf{7 2 . 5 2}$ & $\mathbf{3 6 . 2 3}$ \\
\hline 2L0.9-2L2.7 & $\mathbf{5 3 . 6 2}$ & $\mathbf{4 1 . 4 9}$ \\
\hline 2L1.8-2L2.7 & $\mathbf{2 4 . 3 1}$ & $\mathbf{4 5 . 7 8}$ \\
\hline
\end{tabular}

\begin{tabular}{|c|c|c|}
\hline $\begin{array}{c}\text { Formulations } \\
\text { compared }\end{array}$ & $\mathrm{f}_{1}$ & $\mathrm{f}_{2}$ \\
\hline 3L0.9-3L1.8 & $\mathbf{1 2 0 . 1 5}$ & $\mathbf{2 8 . 5 4}$ \\
\hline 3L0.9-3L2.7 & $\mathbf{1 1 3 . 5 9}$ & $\mathbf{3 1 . 3 3}$ \\
\hline 3L1.8-3L2.7 & $\mathbf{2 5 . 1 3}$ & $\mathbf{4 3 . 1 1}$ \\
\hline 4L0.9-4L1.8 & $\mathbf{9 1 . 2 3}$ & $\mathbf{3 0 . 6 6}$ \\
\hline 4L0.9-4L2.7 & $\mathbf{8 6 . 3 3}$ & $\mathbf{3 2 . 4 2}$ \\
\hline 4L1.8-4L2.7 & $\mathbf{3 7 . 0 4}$ & $\mathbf{3 2 . 7 7}$ \\
\hline
\end{tabular}

\begin{tabular}{|c|c|c|}
\hline $\begin{array}{c}\text { Formulations } \\
\text { compared }\end{array}$ & $\mathrm{f}_{1}$ & $\mathrm{f}_{2}$ \\
\hline 5L0.9-5L1.8 & 9.09 & 73.81 \\
\hline 5L0.9-5L2.7 & $\mathbf{2 4 . 9 9}$ & 54.82 \\
\hline 5L1.8-5L2.7 & $\mathbf{2 0 . 3 2}$ & 59.30 \\
\hline 6L0.9-6L1.8 & $\mathbf{1 5 . 5 9}$ & 68.19 \\
\hline 6L0.9-6L2.7 & $\mathbf{3 9 . 6 3}$ & $\mathbf{4 6 . 5 4}$ \\
\hline 6L1.8-6L2.7 & $\mathbf{3 1 . 2 8}$ & 50.43 \\
\hline
\end{tabular}

Table 3. Comparison of the formulations with the same plasticizer in different content (value of the factors indicating difference are bolded).

\begin{tabular}{|c|c|c|}
\hline $\begin{array}{c}\text { Formulations } \\
\text { compared }\end{array}$ & $\mathrm{f}_{1}$ & $\mathrm{f}_{2}$ \\
\hline 1L0.9-2L0.9 & $\mathbf{2 7 . 2 8}$ & 63.21 \\
\hline 1L1.8-2L1.8 & $\mathbf{4 0 . 5 9}$ & $\mathbf{4 0 . 7 6}$ \\
\hline 1L2.7-2L2.7 & $\mathbf{3 3 . 5 8}$ & $\mathbf{4 0 . 7 1}$ \\
\hline
\end{tabular}

\begin{tabular}{|c|c|c|}
\hline $\begin{array}{c}\text { Formulations } \\
\text { compared }\end{array}$ & $\mathrm{f}_{1}$ & $\mathrm{f}_{2}$ \\
\hline 3L0.9-4L0.9 & $\mathbf{3 8 . 6 6}$ & 60.88 \\
\hline 3L1.8-4L1.8 & $\mathbf{2 1 . 3 2}$ & 50.25 \\
\hline 3L2.7-4L2.7 & $\mathbf{2 2 . 0 0}$ & $\mathbf{4 9 . 0 6}$ \\
\hline
\end{tabular}

\begin{tabular}{|c|c|c|}
\hline $\begin{array}{c}\text { Formulations } \\
\text { compared }\end{array}$ & $\mathrm{f}_{1}$ & $\mathrm{f}_{2}$ \\
\hline 5L0.9-6L0.9 & $\mathbf{2 1 . 4 5}$ & 60.83 \\
\hline 5L1.8-6L1.8 & $\mathbf{2 2 . 8 1}$ & 55.23 \\
\hline 5L2.7-6L2.7 & $\mathbf{1 5 . 2 1}$ & 60.19 \\
\hline
\end{tabular}

Table 4. Comparison of the formulations with different plasticizers in the same concentration (value of the factors indicating difference are bolded).

\begin{tabular}{|c|c|c|}
\hline $\begin{array}{c}\text { Formulations } \\
\text { compared }\end{array}$ & $\mathrm{f}_{1}$ & $\mathrm{f}_{2}$ \\
\hline 1L0.9-3L0.9 & $\mathbf{2 6 . 9 1}$ & 63.73 \\
\hline 3L0.9-5L0.9 & $\mathbf{6 1 . 2 1}$ & $\mathbf{4 8 . 0 9}$ \\
\hline 1L0.9-5L0.9 & $\mathbf{4 5 . 6 3}$ & $\mathbf{4 9 . 4 3}$ \\
\hline 1L1.8-3L1.8 & $\mathbf{4 1 . 4 3}$ & $\mathbf{3 7 . 2 9}$ \\
\hline 3L1.8-5L1.8 & $\mathbf{3 2 . 7 0}$ & $\mathbf{3 5 . 9 4}$ \\
\hline 1L1.8-5L1.8 & $\mathbf{2 8 . 9 5}$ & $\mathbf{4 7 . 7 1}$ \\
\hline 1L2.7-3L2.7 & $\mathbf{4 4 . 4 7}$ & $\mathbf{3 9 . 6 7}$ \\
\hline 3L2.7-5L2.7 & $\mathbf{2 6 . 4 4}$ & $\mathbf{4 2 . 0 2}$ \\
\hline 1L2.7-5L2.7 & $\mathbf{2 1 . 2 6}$ & 50.64 \\
\hline
\end{tabular}

\begin{tabular}{|c|c|c|}
\hline $\begin{array}{c}\text { Formulations } \\
\text { compared }\end{array}$ & $\mathrm{f}_{1}$ & $\mathrm{f}_{2}$ \\
\hline 2L0.9-4L0.9 & $\mathbf{1 9 . 3 3}$ & 72.11 \\
\hline 4L0.9-6L0.9 & 8.44 & 86.93 \\
\hline 2L0.9-6L0.9 & $\mathbf{1 8 . 4 1}$ & 74.04 \\
\hline 2L1.8-4L1.8 & $\mathbf{2 4 . 2 8}$ & $\mathbf{4 7 . 8 9}$ \\
\hline 4L1.8-6L1.8 & $\mathbf{5 1 . 8 8}$ & $\mathbf{3 0 . 4 9}$ \\
\hline 2L1.8-6L1.8 & $\mathbf{4 0 . 1 3}$ & $\mathbf{3 7 . 4 0}$ \\
\hline 2L2.7-4L2.7 & $\mathbf{3 4 . 3 5}$ & $\mathbf{4 3 . 6 6}$ \\
\hline 4L2.7-6L2.7 & $\mathbf{2 4 . 2 2}$ & $\mathbf{4 8 . 5 6}$ \\
\hline 2L2.7-6L2.7 & $\mathbf{3 2 . 9 9}$ & $\mathbf{4 5 . 2 2}$ \\
\hline
\end{tabular}

and limit of quantification was $5.8753 \mu \mathrm{g} / \mathrm{mL}$. The lack of interference was shown by measuring spectra after carrying out the method with blank formulations (i.e. not containing fluconazole) or without any formulation, as shown in Figure 3.

The permeation profiles of fluconazole through the bovine hoof membrane are shown in Figures 4-9.

Comparative permeation profiles for formulations containing lower concentrations of plasticizer $(2.7 \%)$ are shown in Figure 10, while those for the formulations containing higher concentrations of plasticizer (4.5\%) are shown in Figure 11.

Comparisons of the permeation profiles using difference $\left(f_{1}\right)$ and similarity $\left(f_{2}\right)$ factors are shown in Tables 2-4.

Model dependent fitting of the permeation profiles with the zero-order kinetics, first-order kinetics

and Higuchi model is shown in Table 5. The data with the correlation coefficients of $\mathrm{R}^{2}<0.8$ were considered unsuitable. In these formulations, there was a decrease of fluconazole concentration on the 7 th day, and the corrected values, after the discard of data for the 7 th day, are shown in Table 6.

The data with the highest correlation coefficients are bolded, while those with correlation coefficients $\mathrm{R}^{2}<0.8$ are italicized.

\section{DISCUSSION}

Fluconazole is very keratinophilic agent (28), and since it possesses adequate physicochemical properties, as mentioned earlier, it was selected as a good candidate for the treatment of onychomycoses if applied in a formulation for targeted local therapy. 

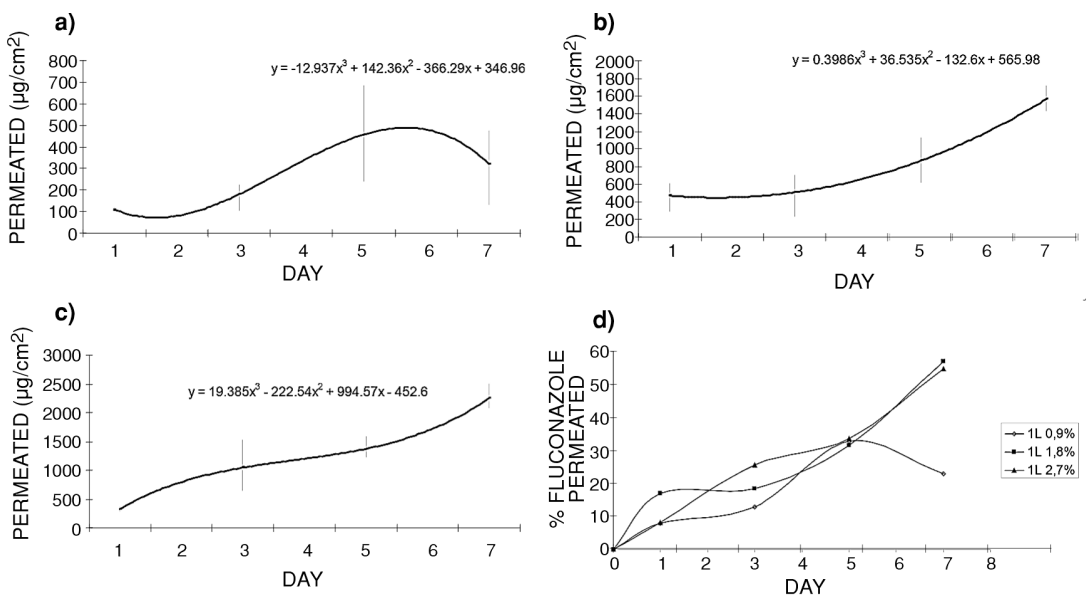

Figure 4. Permeation profiles of formulation $1 \mathrm{~L}$ with fluconazole content a) $0.9 \%$, b) $1.8 \%$, c) $2.7 \%$, and d) comparative permeation profiles for all three strengths of $1 \mathrm{~L}$.
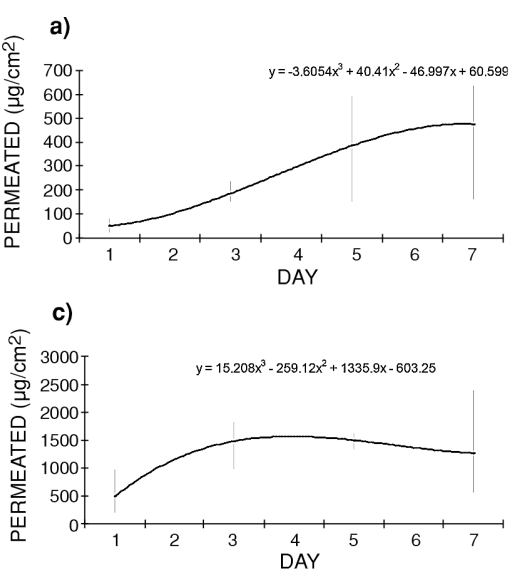

b)

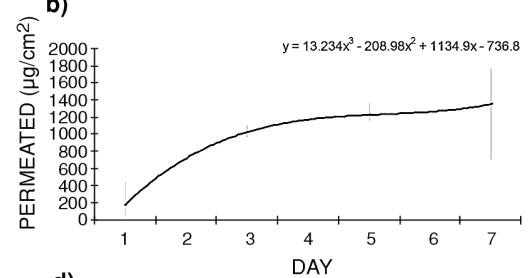

d)

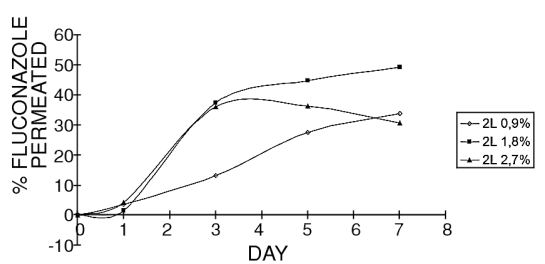

Figure 5. Permeation profiles of formulation $2 \mathrm{~L}$ with fluconazole content a) $0.9 \%$, b) $1.8 \%$, c) $2.7 \%$, and d) comparative permeation profiles for all three strengths of $2 \mathrm{~L}$.

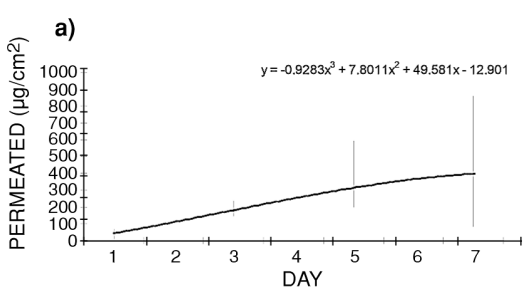

c)

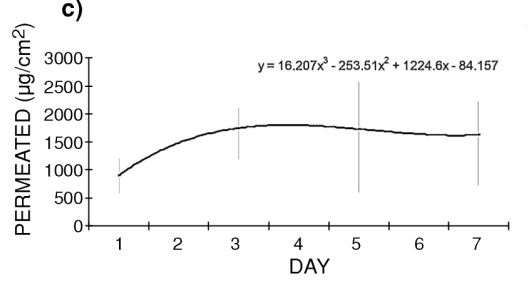

b)

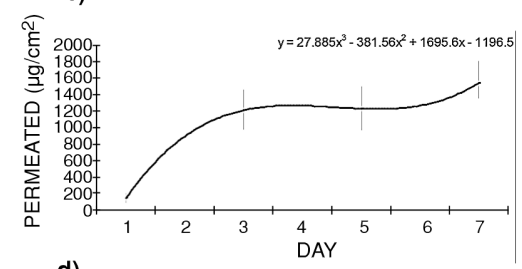

d)

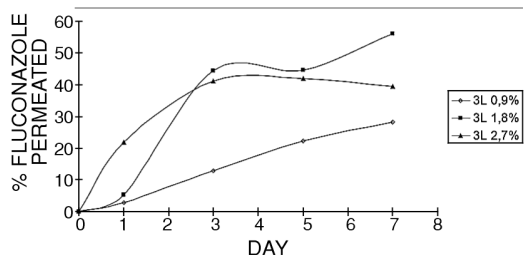

Figure 6. Permeation profiles of formulation $3 \mathrm{~L}$ with fluconazole content a) $0.9 \%$, b) $1.8 \%$, c) $2.7 \%$, and d) comparative permeation profiles for all three strengths of $3 \mathrm{~L}$. 
The influence of plasticizer in nail lacquer formulations on fluconazole...

51

a)

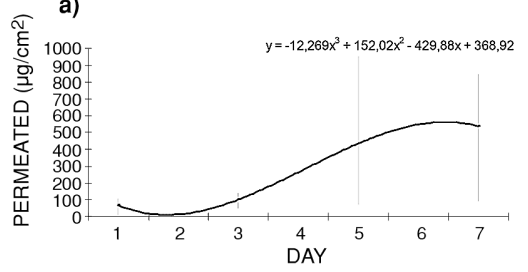

c)

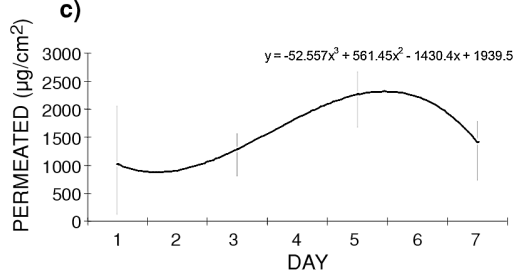

b)

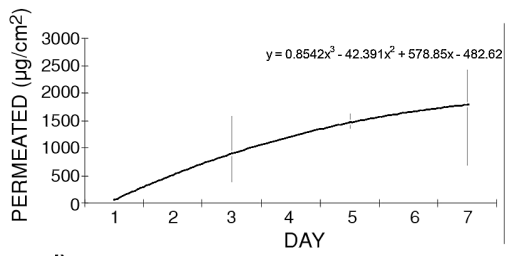

d)

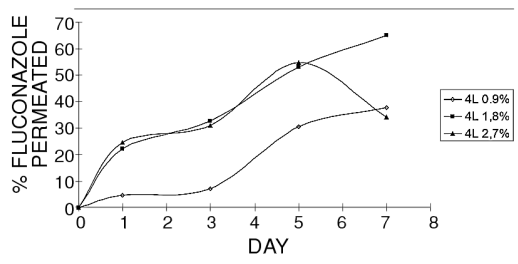

Figure 7. Permeation profiles of formulation $4 \mathrm{~L}$ with fluconazole content a) $0.9 \%$, b) $1.8 \%$, c) $2.7 \%$, and d) comparative permeation profiles for all three strengths of $4 \mathrm{~L}$.

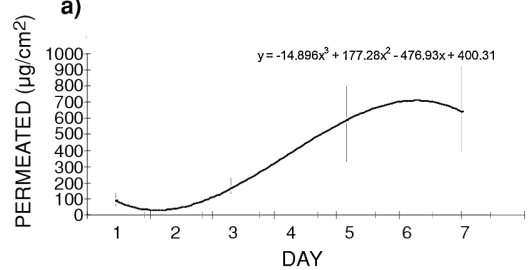

c)

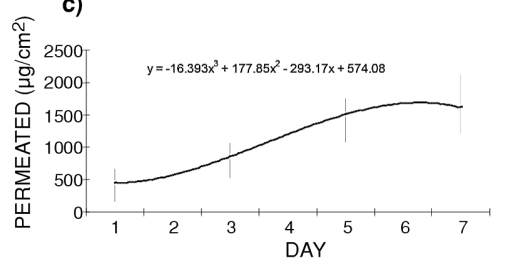

b)

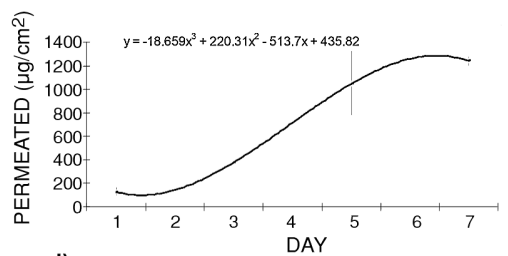

d)

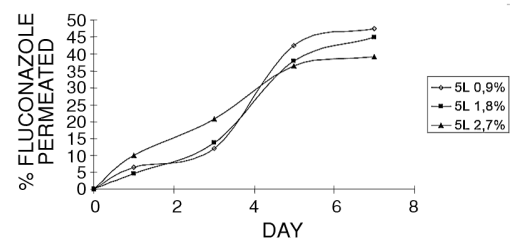

Figure 8 . Permeation profiles of formulation $5 \mathrm{~L}$ with fluconazole content a) $0.9 \%$, b) $1.8 \%$, c) $2.7 \%$, and d) comparative permeation profiles for all three strengths of $5 \mathrm{~L}$.

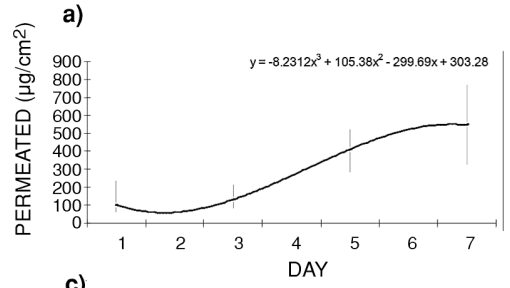

c)

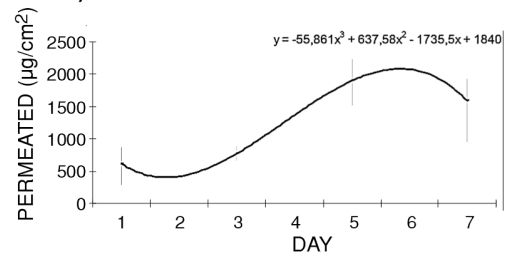

b)

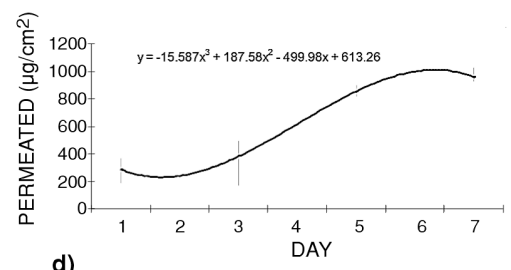

d)

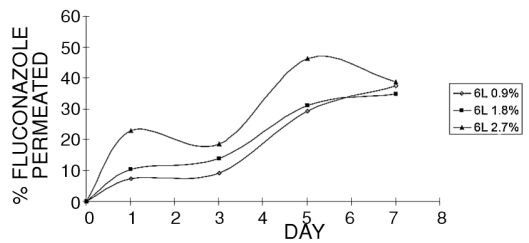

Figure 9. Permeation profiles of formulation $6 \mathrm{~L}$ with fluconazole content a) $0.9 \%$, b) $1.8 \%$, c) $2.7 \%$, and d) comparative permeation profiles for all three strengths of $6 \mathrm{~L}$. 
The acrylic polymer selected for this delivery system is usually used in modified (prolonged) release dosage forms. In this case, it was selected based on a different premise. It is insoluble in water, and as such when applied to the nail plate it would act occlusive and prevent water evaporation from the nail plate. Consequently, the nail plate would be more hydrated and keratin fibers would move apart allowing faster permeation of the active substance.

Different plasticizers were used including lipophilic plasticizer dibutyl phthalate and hydro- philic plasticizers propylene glycol and macromolecular polyethylene glycol 400.

All components are soluble in acetone, which was selected since the polymer, as the substance used in the highest concentration, dissolves fast in it, compared to the other solvents (29), and, thus saves energy and time in production process.

The obtained solutions had low viscosity, i.e. greater mobility, making it easy for the application to the nail plate, upon which the acetone evaporated quickly leaving a homogenous, smooth, transparent and elastic film.

Table 5. Fitting of experimental data of fluconazole permeation from medicinal nail lacquer through the bovine hoof membrane with zero-order, first-order kinetics and Higuchi model. The data with the highest correlation coefficients are bolded, while those with correlation coefficients $\mathrm{R}^{2}<0.8$ are italicized.

\begin{tabular}{|c|c|c|c|c|}
\hline \multicolumn{2}{|c|}{ Formulation } & Zero order & First order & Higuchi \\
\hline \multirow{3}{*}{$1 \mathrm{~L}$} & $0.9 \%$ & 0.5811 & 0.7239 & 0.6296 \\
\hline & $1.8 \%$ & 0.8585 & 0.9203 & 0.7552 \\
\hline & $2.7 \%$ & 0.9737 & 0.9166 & 0.9485 \\
\hline \multirow{3}{*}{$2 \mathrm{~L}$} & $0.9 \%$ & 0.9817 & 0.9026 & 0.9764 \\
\hline & $1.8 \%$ & 0.8251 & 0.7114 & 0.9128 \\
\hline & $2.7 \%$ & 0.4074 & 0.4775 & 0.5403 \\
\hline \multirow{3}{*}{$3 \mathrm{~L}$} & $0.9 \%$ & 0.9888 & 0.8753 & 0.9952 \\
\hline & $1.8 \%$ & 0.7931 & 0.6843 & 0.8765 \\
\hline & $2.7 \%$ & 0.4766 & 0.5077 & 0.6074 \\
\hline \multirow{3}{*}{$4 \mathrm{~L}$} & $0.9 \%$ & 0.9087 & 0.9152 & 0.8585 \\
\hline & $1.8 \%$ & 0.9616 & 0.7605 & 0.9954 \\
\hline & $2.7 \%$ & 0.2696 & 0.3552 & 0.3345 \\
\hline \multirow{3}{*}{$5 \mathrm{~L}$} & $0.9 \%$ & 0.8941 & 0.9161 & 0.8692 \\
\hline & $1.8 \%$ & 0.9514 & 0.9265 & 0.9321 \\
\hline & $2.7 \%$ & 0.9417 & 0.9129 & 0.9563 \\
\hline \multirow{3}{*}{$6 \mathrm{~L}$} & $0.9 \%$ & 0.9249 & 0.9264 & 0.8628 \\
\hline & $1.8 \%$ & 0.9174 & 0.9241 & 0.8860 \\
\hline & $2.7 \%$ & 0.7042 & 0.7836 & 0.7192 \\
\hline
\end{tabular}

Table 6. Corrected values for kinetic models for formulations with low correlation coefficients $\left(\mathrm{R}^{2}<0.8\right)$ over the period of seven days (the values for the first five days were taken).

\begin{tabular}{|c|c|c|c|c|}
\hline \multirow{2}{*}{\multicolumn{2}{|c|}{ Formulation }} & Zero order & First order & Higuchi \\
\hline & & $\mathrm{R}^{2}$ & $\mathrm{R}^{2}$ & $\mathrm{R}^{2}$ \\
\hline $1 \mathrm{~L}$ & $0.9 \%$ & 0.8938 & 0.9691 & 0.82 \\
\hline $2 \mathrm{~L}$ & $2.7 \%$ & 0.7620 & 0.7573 & 0.8459 \\
\hline $3 \mathrm{~L}$ & $2.7 \%$ & 0.7330 & 0.7376 & 0.8210 \\
\hline $4 \mathrm{~L}$ & $2.7 \%$ & 0.9015 & 0.9446 & 0.8298 \\
\hline $6 \mathrm{~L}$ & $2.7 \%$ & 0.8412 & 0.8955 & 0.7565 \\
\hline
\end{tabular}



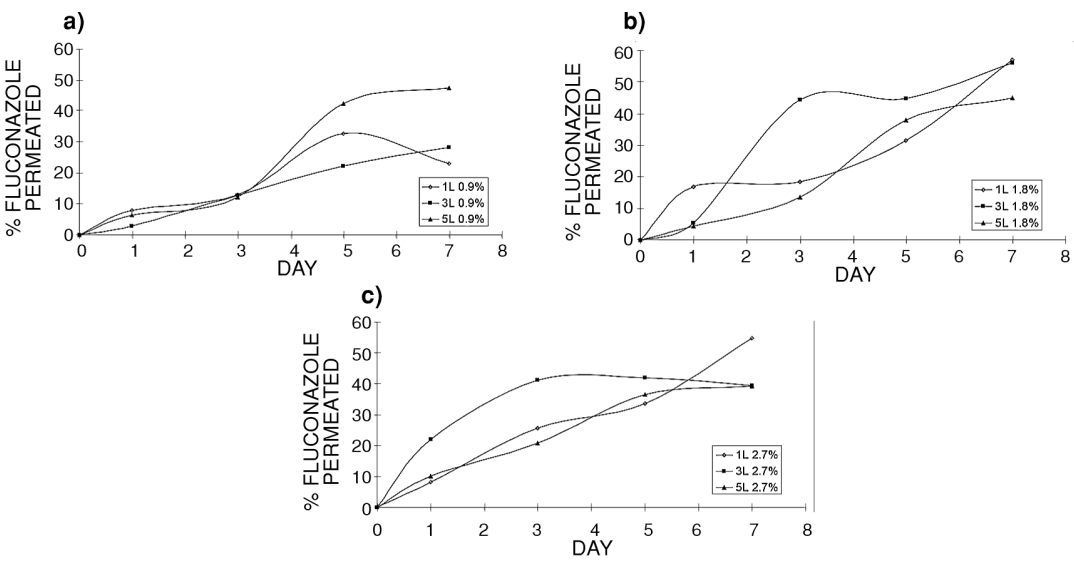

Figure 10. Comparative permeation profiles of fluconazole from formulations $1 \mathrm{~L}, 3 \mathrm{~L}$ and $5 \mathrm{~L}$ with fluconazole content of a) $0.9 \%$, b) $1.8 \%$ and c) $2.7 \%$.
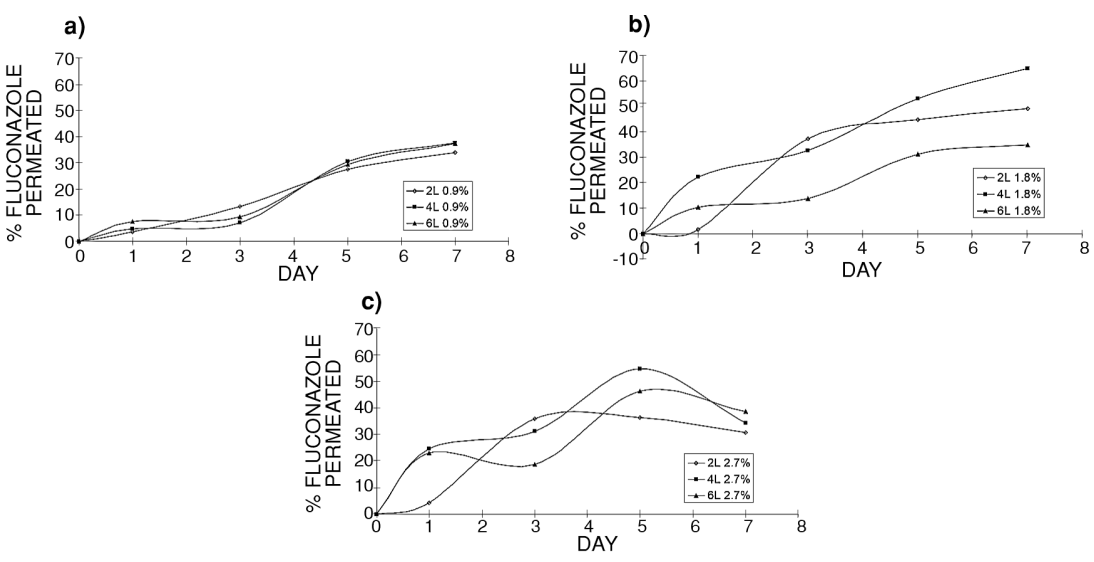

Figure 11. Comparative permeation profiles of fluconazole from formulations $2 \mathrm{~L}, 4 \mathrm{~L}$ and $6 \mathrm{~L}$ with fluconazole content of a) $0.9 \%$, b) $1.8 \%$ and c) $2.7 \%$

\section{Permeability studying method through the bovine hoof membrane}

Bovine hoof membrane is one of the membranes used in transungual permeability studies. It was selected due to its availability and the possibility of the correlations of permeability through the human nail plate. Realistic conditions were strived for, and thus:

- receptor medium was isotonic phosphate buffer $\mathrm{pH} 7.4$, even though according to the literature accounts it might lead to slower permeation compared to the media of weaker ionic strength (15);

- turning the vials upside down enables full contact of the receptor medium with the membrane;

- the lacquer was in contact with the air (it was not used in the form of a receptor solution);
- the system was thermostated at $32^{\circ} \mathrm{C}$, that being the temperature of the skin surface.

The spectra of the receptor media were collected after carrying out the method using only bovine hoof membrane (blind probe), as well as with blank formulations (without fluconazole), after 7 days. Since these samples did not show the absorbance in the wavelength range of interest, the wavelength of $261.0 \mathrm{~nm}$ was selected as one of the fluconazole peaks. The specificity of the method was thus proven.

There is an inherent intraindividual and interindividual variability of the natural membrane, such as bovine hoof membrane. This method enables insight into the extent of permeation of the active substance through the keratinous formation, 
like bovine hoof membrane or nail plate, but it cannot give reproducible results.

This method is inexpensive, non-toxic, i.e. ecologically acceptable. However, it is time-consuming and requires a lot of manual labor. Since it is a spectrophotometric method, it uses a relatively large amount of sample (receptor medium from one vial). Thus, the permeability of the active substance cannot be studied over time, but only the end point - the sampling is the end of the experiment. The obtained permeability profiles were, thus, sets of the end points of individual experiments, not monitoring of the active substance permeability over one membrane over time. This might also be an advantage, since each obtained permeability profile of fluconazole was the image of the flux through several membranes, not one, thus decreasing the importance of the variability of individual membranes.

\section{Fluconazole permeation kinetics through the bovine hoof membrane}

There is a unique characteristic of nail lacquers as dosage forms. Namely, the formulations are in liquid form and then the concentrations of fluconazole are $0.9 \%, 1.8 \%$ or $2.7 \%$, in this case. However, fluconazole penetrates the nail plate from solid film, i.e. dried lacquer, where the concentrations of fluconazole are significantly higher $-4.5 \%, 8.5 \%$ or $12 \%$, respectively. This was taken into account in calculations, even though the denomination of formulations were kept at $0.9 \%, 1.8 \%$ and $2.7 \%$.

The permeation profiles of formulations $1 \mathrm{~L}-$ 6L are given in Figures 4-9 and comparative permeation profiles of different formulations are shown in Figures 10 and 11 . Formulations $1 \mathrm{~L}$ and $2 \mathrm{~L}$ contained dibutyl phthalate as plasticizer in concentrations of $2.7 \%$ (1L) and $4.5 \%$ (2L). Dibutyl phthalate is a lipophylic plasticizer miscible with acetone, but not with water. It gives tough films, and both formulations should occlude the membrane well, making it well hydrated.

From formulations with concentrations of $2.7 \%$, the level of fluconazole permeation from formulation 2L was noticeably lower (7th day $~ 1500$ $\mu \mathrm{g}$ ), compared to the $1 \mathrm{~L}$ (7th day $~ 2500 \mu \mathrm{g}$ ). Dibutyl phthalate in formulation $2 \mathrm{~L}$ was in higher concentration making polymer chains more mobile and the film more sinewy. In this case, it seems that fluconazole was retained in the film more than it permeated the membrane, probably dissolved in dibutyl phthalate (Figs. 4 and 5).

Fluconazole permeation profiles did not vary significantly at fluconazole concentration of $0.9 \%$ (similarity factor $\left(f_{2}\right)$ being considered a more dis- criminatory indicator that the difference factor $\left(\mathrm{f}_{1}\right)$ ). However, there was a notable difference in concentrations of $1.8 \%$ and $2.7 \%$, as is confirmed by both $\mathrm{f}_{1}$ and $\mathrm{f}_{2}$ (Table 3 ). While the continued increase in permeated fluconazole over 7 days was seen from formulations $1 \mathrm{~L}$, there was a jump from day 1 to 3 from formulations $2 \mathrm{~L}$, after which it reached near plateau over the next four days. This lead to the conclusion that from formulation $2 \mathrm{~L}$, the amount of fluconazole that was released and permeated the membrane was the amount controlled/allowed by the film, after which the equilibrium concentrations were established in the film, membrane and receptor medium, with the film being the limiting factor for permeation of fluconazole from such formulation. This was later confirmed since the kinetics of permeation of fluconazole mathematically agreed with the Higuchi release model (Table 5).

Formulations $3 \mathrm{~L}$ and $4 \mathrm{~L}$ contained polyethylene glycol 400 (PEG 400) as a plasticizer in concentrations of $2.7 \%$ (3L) and $4.5 \%$ (4L). PEG 400 is a hydrophilic polymeric plasticizer, miscible both in acetone and water. It forms films with large pores, enabling faster release of the active substance from the film.

The higher concentration of plasticizer leads to larger pores, but less nail occlusion by acrylates, thus its less hydration. Again, the differences in formulations were more pronounced at higher fluconazole concentrations (1.8\% and $2.7 \%$ ). In $3 \mathrm{~L}$ formulations, there was a sudden release of fluconazole that reached its maximum after three days. On the other hand, the level of permeated fluconazole by day 3 was significantly smaller in formulations $4 \mathrm{~L}$ (all three strengths), but after day 5, the overall amount permeated became somewhat higher from these formulations, compared to 3L (Figs. 6 and 7).

Comparing the two formulations of the same strengths, the similarity and difference factors indicate that the profiles differed by about $10 \%$ (that being the boundary of similar/dissimilar binning), and thus their kinetics was more dependent of fluconazole concentration, then the plasticizer content (Tables 2 and 3).

Formulations $5 \mathrm{~L}$ and $6 \mathrm{~L}$ contain propylene glycol as a plasticizer in concentrations of $2.7 \%(5 \mathrm{~L})$ and $4.5 \%$ (6L). Propylene glycol a hydrophilic plasticizer, miscible with both acetone and water, enabling faster dissolution of the other ingredients in these solutions during production.

It can be considered that the permeation profiles were similar when comparing the same formulations with different strengths, as well as when comparing the same strengths of these two formula- 
tions (Table 2 and 3). Thus, when using propylene glycol as plasticizer, its characteristics are more important than its concentration.

In both formulations, there was a notable sigmoid permeation profile curve (Figs. 8 and 9). In all three strengths of both formulations, the curves were concurrent during the first three days. However, there was noticeable dominance of the 6L formulations, where fluconazole permeated in somewhat larger extent. It was interesting that this trend could be seen in formulations $3 \mathrm{~L}$ and $4 \mathrm{~L}$, which also contain hydrophilic plasticizer, while in formulations with lipophilic plasticizer (1L and $2 \mathrm{~L}$ ), the trend was reversed. Thus, with a higher concentration of hydrophilic plasticizer, the film was created with larger pores and more mobile matrix that enabled increased permeation of fluconazole. Even though the increase in plasticizer concentration was relatively large, the permeation increased for $\sim 10 \%$.

The formulations with lower plasticizer levels ( $2.7 \%$, i.e. $15 \%$ compared to the polymer) were also compared (Table 4). In the lowest strength formulations $(0.9 \%)$, due to the decrease of fluconazole that permeated on day 7 from formulation 1L, there was a large varying in the overall extent of permeation ( $23 \%$ from 1L to $47.49 \%$ from $5 \mathrm{~L}$ ). However, in $1.8 \%$ and $2.7 \%$ formulations, there was a notable dominance of $1 \mathrm{~L}$ formulation $(39 \%$ from $3 \mathrm{~L}$ and $5 \mathrm{~L}$, $54.7 \%$ from 1L) (data shown graphically in Fig. 10). Also, the permeation kinetics from $3 \mathrm{~L}$ and $5 \mathrm{~L}$ obeyed the Higuchi model, while from 1L permeation, it followed the zero-order kinetics at the highest concentration of fluconazole (Table 5).

When comparing the formulations with higher plasticizer concentrations $(4.5 \%$, i.e. $25 \%$ compared to the polymer), the profiles are concurrent at the lowest fluconazole strength (Table 4). At 1.8\% fluconazole concentration, the extent of permeation varied after seven days: from $6 \mathrm{~L}-34.9 \%$, from $2 \mathrm{~L}-$ $49.25 \%$ and from $4 \mathrm{~L}-65 \%$ (data shown graphically in Fig. 11). This confirmed literature data on polyethylene glycol 400 as a plasticizer which enables the better release of the active substance from films.

In all three formulations with $2.7 \%$ fluconazole, there was a decrease in fluconazole concentration in receptor medium after day 5 . The main characteristics of these formulations are the highest content of fluconazole and the highest content of plasticizer.

After the fifth day, the concentration of fluconazole in receptor fluid decreased, thus fluconazole could be either in the membrane or in the lacquer film. Plasticizers, as mentioned earlier, are located between polymeric molecules, causing their greater mobility, and thus higher permeation of active substance. It was hypothesized that after longer application period (more than 5 days) plasticizer itself entered the membrane and there acted in the same fashion moving apart keratin chains, thus opening more binding sites for keratinophilic fluconazole, that was withdrawn from receptor solution back to the membrane. This was pronounced in formulations with higher plasticizer content (25\% compared to the acrylate).

Permeation of fluconazole from nail lacquers through the bovine hoof membrane followed the first-order kinetics or Higuchi model kinetics (Tables 5 and 6).

Thus, permeation kinetics depended on fluconazole concentration in the formulation as well as on the distance the active substance needed to pass to permeate from the film through the membrane and into the receptor solution.

\section{CONCLUSION}

The transungual delivery system (nail lacquer) formulations of fluconazole were developed with Eudragit RS100 with suitable plasticizers enabling the formation of homogenous, smooth, transparent and elastic films. Permeation studies were carried out using the developed method of in vitro permeation across the bovine hoof membrane during 7-day period and the obtained permeability profiles analyzed using similarity and difference factors, and also by model-dependent permeation kinetics. When analyzed within the same strength, the highest extent of fluconazole permeation was obtained from formulation $5 \mathrm{~L}$ at $0.9 \%$ fluconazole concentration, while for $1.8 \%$ and $2.7 \%$ of fluconazole, the highest permeation was achieved from formulation $4 \mathrm{~L}$. The permeation profiles showed greater difference within one formulation of different fluconazole content, then with the same plasticizer $(15 \%$ or $25 \%$ compared to the polymer), especially when using dibutyl phthalate and PEG 400. Permeation profiles were similar when using propylene glycol, considering both different concentrations of fluconazole and the plasticizer. When comparing formulations with the same concentration of plasticizers, there were perceivable differences in formulations with higher fluconazole concentrations, while the profiles were similar at $0.9 \%$ fluconazole. Permeation kinetics depended on fluconazole concentration as well as the path length the active substance had to pass to reach the receptor solution.

\section{Conflict of interest}

The authors declare no conflicts of interest. 


\section{REFERENCES}

1. Murdan S.: Int. J. Pharm. 236, 1 (2002).

2. Repka M.A., Mididoddi P.K., Stodghill S.P.: Int. J. Pharm. 282, 95 (2004).

3. Hui X., Shainhouse Z., Tanojo H., Anigbogu A., Markus G.E., et al.: J. Pharm. Sci. 91, 189 (2002).

4. Baran R., Kaoukhov A.: JEADV. 19, 21 (2005).

5. Marty J.-P.L.: JEADV. 4 (Suppl.1), S17 (1995).

6. Saner M.V., Kulkarni A.D., Pardeshi C.V.: J. Drug Target. 22, 769 (2014).

7. Consejo General de Colegios Oficiales de Farmacéuticos: Cosmetologia teorico - practica, Coop, COIMOF, Madrid 1978.

8. Salvador A., Chisvert A.: Analysis of Cosmetic Products, Elsevier, Amsterdam 2007.

9. Lin S.-Y., Chen K.-S., Run-Chu L.: J. Control. Release 68, 343 (2000).

10. Siepmann F., Siepmann J., Walther M., MacRae R.J., Bodmeier R.: J. Control. Release 125, 1 (2008).

11. Siepmann J., Lecomte F., Bodmeier R.: J. Control. Release 60, 379 (1999).

12. Fadda H.M., Hernández M.C., Margetson D.N., McAllister S.M., Basit A.W., et al.: J. Pharm. Sci. 97, 3957 (2008).

13. Walters K.A., Flynn G.L.: Int. J. Cosmet. Sci. 5, 231 (1983).

14. Dash A.K., Elmquist W.F.: Fluconazole, in Analytical Profiles of Drug Substances and Excipients. Brittain H.G. Ed., Vol. 27, Academic Press, San Diego 2001.

15. Kobayashi Y., Komatsu T., Sumi M., Numajiri S., Miyamoto M., et al.: Eur. J. Pharm. Sci. 21, 471 (2004).

16. Christensen L., Turner R., Weaver S., Caserta F., Long L., et al.: Antimicrob. Agents Chemother. 61, e02554 (2017).
17. Cutrín Gómez E., Anguiano Igea S., DelgadoCharro M.B., Gómez Amoza J.L., Otero Espinar F.J.: Eur. J. Pharm. Biopharm. 128, 48 (2018).

18. Samour C.M., Krauser S.F.: Antifungal nail lacquer and method using same. US Patent No. 6224887 (May 1, 2001).

19. Myoung Y., Choi H-K.: Eur. J. Pharm. Sci. 20, 319 (2003).

20. Mohorčič M., Torkar A., Friedrich J., Kristl J., Murdan S.: Int. J. Pharm. 332, 196 (2007).

21. Hui X., Wester R.C., Barbadillo S., Lee C., Patel B., et al.: J. Pharm. Sci. 93, 2545 (2004).

22. International Council for Harmonization of Technical Requirements for Pharmaceuticals for Human Use: ICH Harmonised Tripartite Guideline: Validation of Analytical Procedures: Text and Methodology Q2(R1), Geneva 2005.

23. Food and Drug Administration, Center for Drug Evaluation and Research: Guidance for industry: Immediate release solid oral dosage forms. Scale-up and postapproval changes: chemistry, manufacturing, and controls, in vitro dissolution testing, and in vivo bioequivalence documentation, Hampton 2015.

24. Singhvi G., Singh M.: Int. J. Pharm. Stud. Res. 2, 77 (2011).

25. Costa P., Sousa Lobo J.M.: Eur. J. Pharm. Sci. 13, 123 (2001).

26. Ramteke K.H., Dighe P.A., Kharat A.R., Patil S.V.: Sch. Acad. J. Pharm. 3, 388 (2014).

27. Siepmann J., Peppas N.A.: Adv. Drug Del. Rev. 48, 139 (2001).

28. Baran R., Coquard F.: J. Dermatolog. Treat, 16, 52 (2005).

29. Kibbe A.H. Ed.: Handbook of Pharmaceutical Excipients, 3rd ed., Pharmaceutical Press, London 2000.

(c) 2020 by Polish Pharmaceutical Society. This is an open access article under the CC BY NC license (c) (1) () (http://creativecommons.org/licenses/BY/4.0/). 